\title{
An Evaluation of Destination Management Systems in Madagascar with Aspect of Tourism Sector
}

\author{
Daré Aurélien, Rakotonirina Jeremy Desiré \\ School of Economics and Management, China University of Geosciences, Wuhan, China \\ Email: dareaurelien@gmail.com, jierui6@yahoo.fr
}

Received 11 July 2014; revised 6 August 2014; accepted 5 September 2014

Copyright $@ 2014$ by authors and Scientific Research Publishing Inc.

This work is licensed under the Creative Commons Attribution International License (CC BY). http://creativecommons.org/licenses/by/4.0/

(c) (i) Open Access

\begin{abstract}
This paper describes the Destination Management Systems (DMS). Madagascar is a developing country in Africa and has a big population. Madagascar is one of the beautiful countries with its attractive beautiful scenery. These sceneries, lakes and beaches of Madagascar always attract travelers from all over the world to come to Madagascar to enjoy the nature, so a portion of this paper discusses about the tourism sector of Madagascar. No doubt Madagascar is gaining some money from tourism sector, but it can be increased if there can be a strong DMS for the traveler. The overall Destination Management Systems (DMS) and tourism sector of Madagascar have been discussed in this paper. As per conclusion, we can say DMS could increase visitor traffic, attract the right market segment with the provision of an accurate and up to date comprehensive electronic database. DMS also supports the wide distribution of destination information online. DMS can also help to create more efficient internal and external networks, which can have long-term positive effects on the local economy in achieving competitiveness.
\end{abstract}

\section{Keywords}

Madagascar, Tourism, Destination Management Systems (DMS), Economy

\section{Introduction}

The Republic of Madagascar is a country located in Eastern Africa, consisting of the world's fourth largest island and some smaller islands in the Indian Ocean. Madagascar has a coastal plain, high plateau and mountains. Major rivers include the Betsiboka, Onilahy, Mangoky and Tsiribihina. The east coast of Madagascar has lowlands leading to steep bluffs and central highlands. The Tsaratanana Massif in the north has volcanic mountains. 
The west coast has many protected harbors and broad plains, while the southwest is a plateau and desert region. The largest city and capital is Antananarivo. Other important cities are Antsirabe, Mahajanga and Toamasina. The highest peak is the Maromokotro, reaching 2876 meters above sea level. Madagascar, the 4th largest island in the world with a surface area of $587,014 \mathrm{~km}$, is known in the world due to the quality and diversity of its natural wealth of flora and fauna. The country also enjoys great geomorphologic diversity, such as the Tsingy de Bemaraha in the north, a UNESCO World Heritage site or the Massif in the south (Figure 1). The Republic of

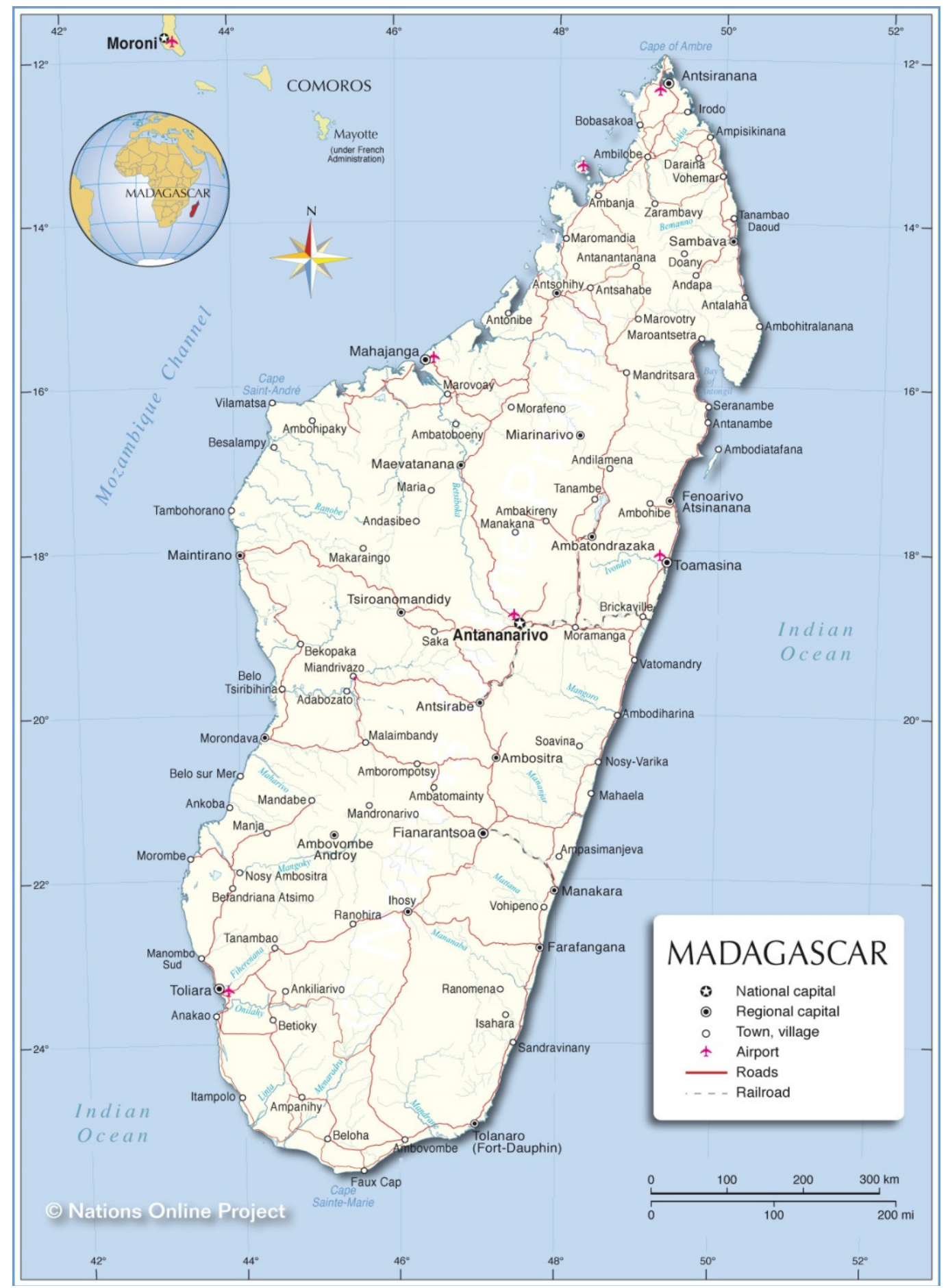

Figure 1. Madagascar globally location and political map. 
Madagascar is an island with a total area of 587,040 sq. km (land: 581,540 sq. km, water: 5500 sq. km) located in the southern parts of Africa in the Indian Ocean, East of Mozambique. The tourism sector is a dominant source of foreign exchange earnings. The sector accounts for one fourth of earnings, originating from services and is growing at $20 \%$ per year. The country is endowed with superb tourist sceneries (Diego Suarez's region-Antsiranana-in the north of the country for instance).

A Destination Management System (DMS) is a term for a specialized services company possessing wideranging local knowledge, expertise and resources, specifying in the design and application of events, activities, tours, transportation and program logistics. A DMS provides a ground service founded on local knowledge of their given termini. These facilities can be in the shape of transportation, hotel accommodation, restaurants, activities, excursions, conference venues, themed events, gala dinners and logistics, meetings, incentive schemes as well as helping with overcoming language barriers. These functions usually performed by travel agents and tour operators.

The types of DMO can be:

- National Tourism Authorities (NTAs) or Organisations (NTOs), responsible for management and marketing of tourism at a national level.

- Regional, provincial or state DMOs, responsible for the management and/or marketing of tourism in a geographic region defined for that purpose.

- Local DMOs, responsible for the management and/or marketing of tourism based on a smaller geographic area or city/town.

- Product Based—bringing together stakeholders related to a specific type of tourism product (i.e. Bird watching, adventure, etc.).

Destination Management Organization will be a leading and most significant body to manage a Destination developing into a "total destination management system". The DMS will become the final source of strategic aptitude and grow as a communication center for a destination. The DMSs community will be required after by Govt. organizations and large establishments for information and leadership [1]. In general, the modest performance of administrations is cleared from the input and output side. The input quantity is based on physical and human capital award and research and growth expenses. The output side covers profitability, market share, productivity, growth and so on [2]. The output side is market share both in the number of entrances and the amount of tourism revenues, productivity and so on. As [3] Pearce (1997) implies, a competitive investigation refers to comparative studies. Therefore, destination attractiveness can be calculated both quantitatively and qualitatively. Quantitative performance of a destination can be measured by looking at numbers such as annual numbers of tourist arrivals, amount of annual tourism receipts, level of expenditure per tourist, length of overnight stays. Destination Marketing System (DMS) can act as organizers to accomplish the strategic objectives of the purpose. [4] Buhalis (2000) declared about these as attract the long-term feasibility of the local population, provision of visitor satisfaction and maximizing profits for Small Medium-Sized Tourism Enterprises. In the present time the demand of new techniques of information has been increased. With new information technologies obligating heightened over the last decade it is of paramount importance DMS in world and some developed countries like Madagascar re-engineer their business process, develop new business models and take advantage of these new tools [5]. Destination Management Systems (DMS) can be described as the IT structure of the Destination Management Organization DMO [6]. DMS should be able to act as an allowing machinery to assimilate the different services and products from the tourism industry. In the field of information and communications technologies (ICTs), Madagascar is presently performing a keen interest, with in specific a firm willingness on the part of the government to draw up a determined national policy with the goal of mixing the country in the global information society by 2010. It is in this environment that we are exploring the future of e-tourism in Madagascar and, in specific, the possibility of a destination management system for Madagascar being set up.

DMS should not only help to hand pre-trip, post arrival information requests, but also assimilate an availability and booking service too [7] [8]. DMS could increase visitor traffic, attract the right market segment with the provision of an accurate and up to date comprehensive electronic database [9]. DMS can also help to create more efficient internal and external networks, which can have long-term positive effects on the local economy in achieving competitive advantage. DMS also support the wide distribution of destination information online. WTO (2001) has showed that a number of new electronic circulation channels are developing through online travel agencies, search directories and destination portals. Therefore an important technical thought in the design 
of DMS is the development of open systems so that links can be developed with alternative circulation channels [9]. Alternative circulation channels are mandatory to support DMS to interface and distribute information through websites, TICs, call centers, kiosks and traditional marketing channels [10]. Therefore DMS need to realize it to act as an enabler in sustaining modest improvement [11] [12].

\section{Tourism Sector of Madagascar}

Tourism is a multidimensional movement that includes not only drives the people from one place to another, but also undertakes both directly and indirectly interweaved towards the easing of this process [13]-[15]. The tourism industry is consequently a compound phenomenon which includes deal processes that are determined by global effects of multinational tourism and travel corporations, geo-political and other broader forces of economic change [16]. As such, tourism produces vast economic movement worldwide and has grown to be one of the world's largest businesses in terms of volume and revenue created. The development of the tourism industry has been remarkable, with international tourist arrivals growing from 25 million in 1950, to 277 million in 1980, to 438 million in 1990, to 681 million in 2000, and currently standing at 880 million [17]. The tourism industry can be a major source of government income in Eastern Africa especially for those countries whose GDP role by the industry is expressively high.

The demand of Information \& Communication Technologies (ICTs) is raising the performance of tourism firms, but also of tourism destinations at a macro-economic level is widely encouraged [18]-[20]. The entirety of the ICTs advanced by Destination Management Organisations (DMO) for marketing their destinations represents the Destination Management System (DMS) of the destination. In general, DMS are considered as inter-organizational ICT directing to link the physically disconnected tourism supply with the tourism demand. For example, [21] defined the DMS as an inter-organizational system that contacts tourist products, suppliers and offers, with consumers and mediators in order to enable easy access to complete and up-to-date destination information and to allow reservations and purchases. A more full DMS definition was newly established from a Delphi study that took into concern the responses of several tourism stakeholders [22]: “...DMS are systems that consolidate and distribute a comprehensive range of tourism products through a variety of channels and platforms, generally catering for a specific region, and supporting the activities of a DMO within that region. DMS attempt to utilise a customer centric approach to manage and market the destination as a holistic entity, typically providing strong destination related information, real-time reservations, destination management tools and paying particular attention to supporting small \& independent tourism suppliers”.

So it's clear from the above mentioned statement that the major role of DMS is to act as electronic in-between providing functionalities connected to e-distribution, e-marketing and e-sales for the whole destination and its tourism suppliers. Indeed, the impact and the necessity of DMS for the survival and the competitiveness of small and medium tourism enterprises (SMTEs) is considered so indispensable, specifically when considering that although SMTEs represent the majority of firms at many destinations, they lack the technological, managerial and financial resources for exploiting ICTs for e-commerce and e-marketing purposes. Therefore, SMTEs heavily depend on DMS for having an e-presence and an alternative e-distribution channel that may in turn reduce their dependencies on tour operators and other intermediaries [19] [22] [23]. Moreover, it should also be highlighted that DMS should serve a much wider role that first aims to support a sustainable development and management of destinations by supporting the marketing and development of sustainable forms of tourism. In Figure 2, we can see the upstream and downstream values of overall tourism sector.

\section{The Tourism Value Chain}

Tourism can be called as a leading economic activity in many Small Island Developing States (SIDS) and a key component of their progress strategies [25]. The Indian Ocean Islands, of which Madagascar, Mauritius, Reunion, Maldives and Seychelles remain the most important tourist destinations, depend on to varying extent on tourism for economic development. The involvement of the travel and tourism industry (TTI) to these island economies cannot ignore. Table 1 provides a summary of the main features of the TTI for the above-mentioned islands in 2010 with respect to the input of tourism to Gross Domestic Product (GDP), direct employment, earnings from tourism, and investment in tourism. Obviously, these data recommend that Maldives and Seychelles are the most reliant on the tourism industry for economic development and Madagascar was gaining 12.7\% from the tourism sector to the GDP of the country in 2010. However, the highest incomes and investment in 


\section{Upstream or backward linkages}

Basic infrastructure services:

water, energy, telecom, sanitation \& solid waste management services

Goods and services needed to build primary tourism facilities: contruction services, manufactured supplies

Goods and services needed to meet operational requirements: agriculture and manufacturing, passenger transportation, hospitality, maintenance \& repair and business services
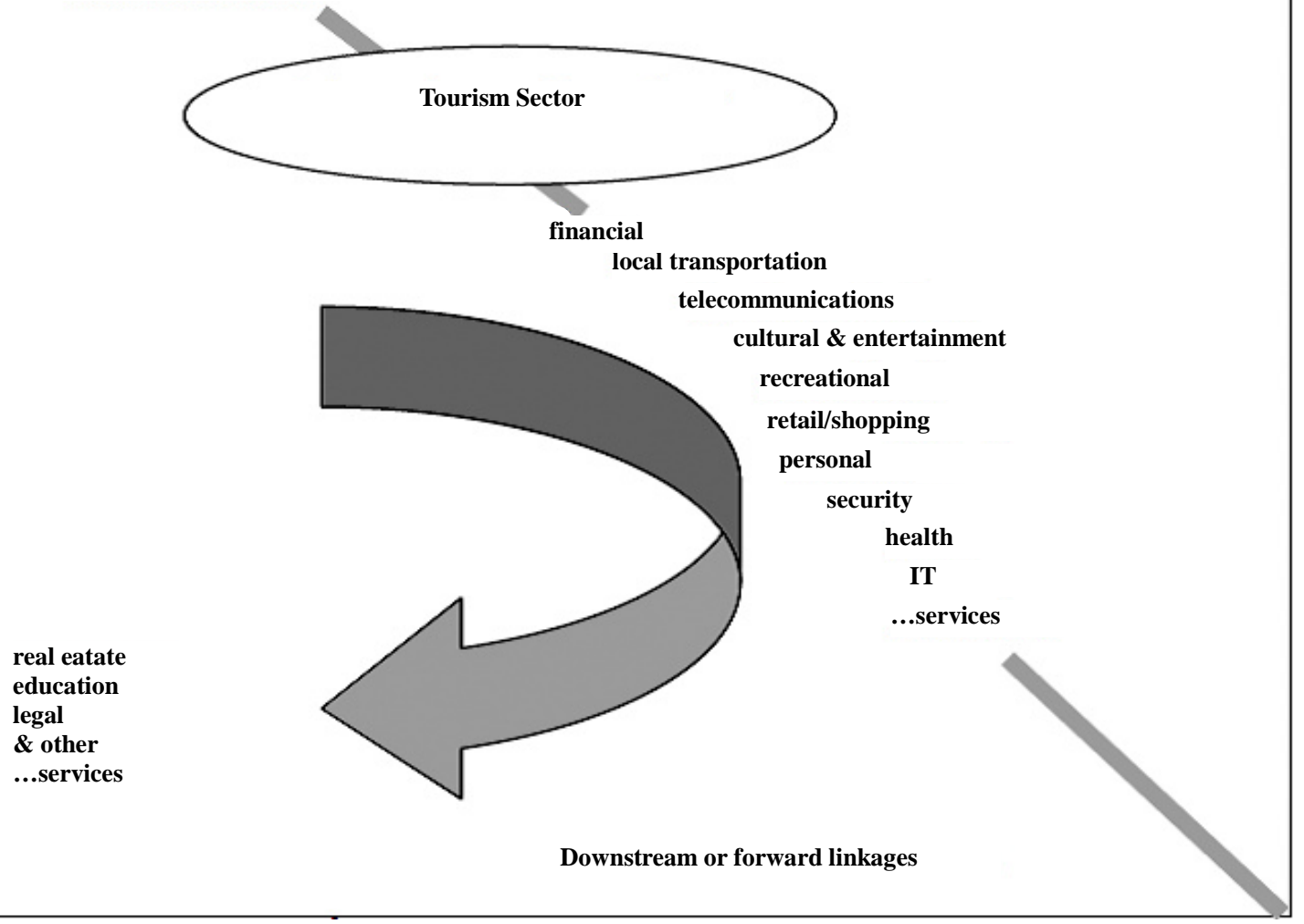

\section{Figure 2. UNCTAD (2007) [24].}

tourism are for Mauritius and Madagascar individually, suggesting that the attractiveness of these islands varies. In fact, Mauritius and Barbados are the only two islands to rank in the top 50 countries, 40th and 30th respectively, for overall destination competitiveness on the Travel and Tourism Competitiveness Index [26].

Travelers from all over the world have always been attracted to Madagascar by its abundant of natural resources (fauna, flora, geomorphology, and climate) and famous and well known cultural resources. At the present time Tourism in Madagascar has been increased over the last twenty years with an annual growth rate which can see in Figure 3. Madagascar is progressively positioning itself as a prime eco-tourism destination. Madagascar is not only gaining revenue from this sector but also a number of Madagascar citizens are belong to this sector for their income, so it also one of the main source of people. In Table 1, we can see the number of people belong to this profession.

In some countries where tourism plays a very significant role ensuring economic growth, it is collective to find cases in which the pressure to grow the sector justified an extremely fast growth and absence of destination planning. So, especially in destinations which have attentive on the so-called Sun and Sea Tourism, physical problems arose, originating from extreme attentions at different, though connected levels. 
Table 1. Tourism employment in select Eastern Africa countries within 2010.

\begin{tabular}{ccc}
\hline & \multicolumn{2}{c}{ Direct and Indirect Employment through Tourism } \\
\cline { 2 - 3 } & No. Employed & \% Working Population \\
\hline Seychelles & 22,000 & $56 \%$ \\
Madagascar & 455,000 & $10.1 \%$ \\
Kenya & 439,000 & $7.3 \%$ \\
Ethiopia & Over 1.6 million & $6.9 \%$ \\
Rwanda & 122,000 & $6.6 \%$ \\
Tanzania & 624,000 & $6.3 \%$ \\
Uganda & 381,000 & $5.9 \%$ \\
Comoros & 10,000 & $5.4 \%$ \\
DRC & 472,000 & $3.1 \%$ \\
Burundi & 53,000 & $3 \%$ \\
\hline
\end{tabular}

Source: WTTC, 2010 [27].
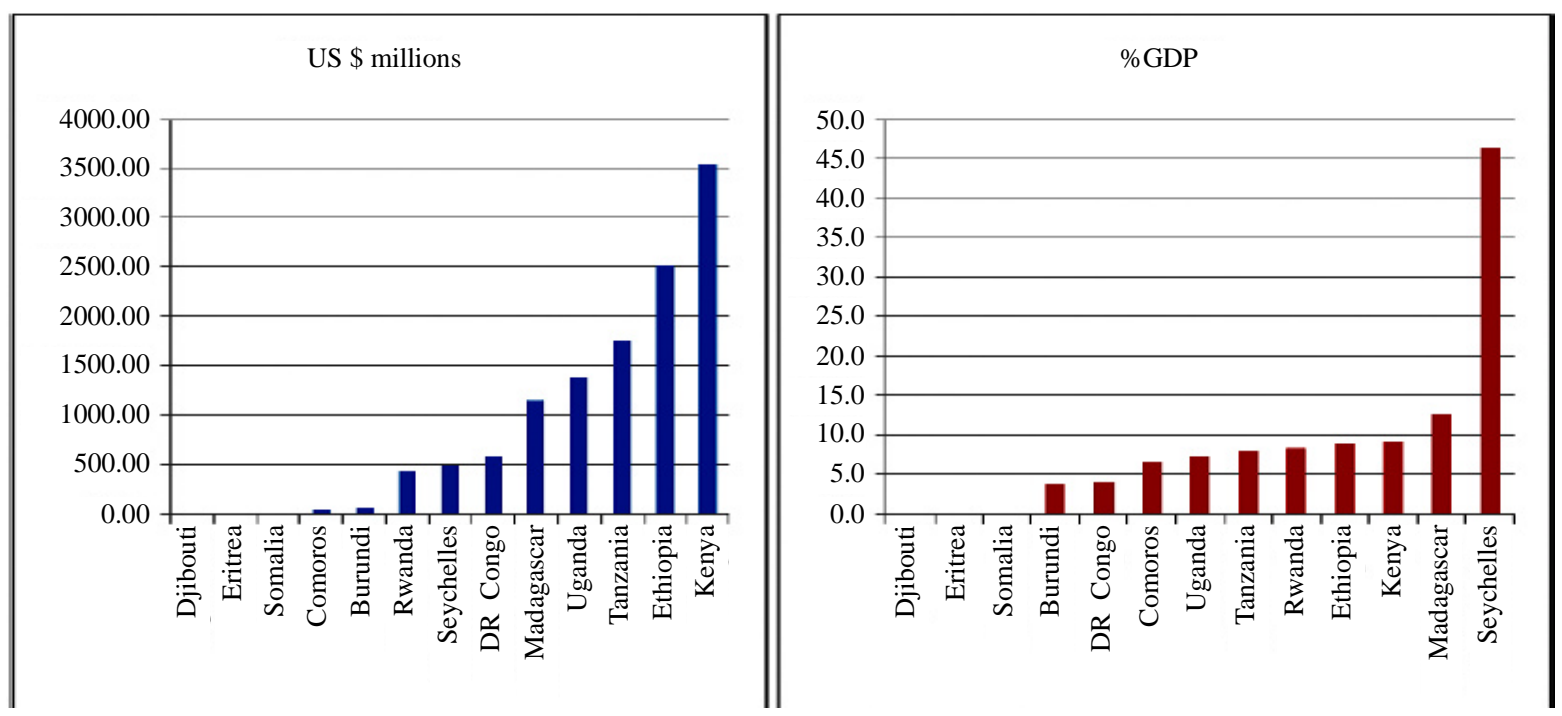

Figure 3. Travel and tourism GDP contribution in Eastern Africa, 2010. Sources: WTTC, 2010 [27].

\section{Some Effects of Tourism Development in Eastern Africa}

Possession and constant growth of relevant tourism abilities and knowledge is essential in the creation of human capital, which is an acute resource for the development of a modest sustainable destination [28]. In the Eastern Africa region, the absence of relevant expertise and knowledge has been a problem for effective tourism development [29]. There have been concentrated efforts, particularly by the more mature tourism destinations, to address this challenge.

However, it is equally important to note that the level of local investment in the tourism industry and the general contribution of the industry in addressing the various developmental challenges have been insignificant in the region [30]. This is could be credited to the fact that these tourism training creativities have been in retort to specific skills lacks within the industry, which is conquered by large initiatives, instead of laying stress on basic skills and knowledge to facilitate, for instance, small enterprise development [30]. The rigidity of the training programmes in Eastern Africa especially in Madagascar has caused in very few people being equipped with the suitable skills and knowledge necessary to raise local efficiency and produce wealth through tourism develop- 
ment [28]. One more major challenge facing tourism development in the Eastern Africa region, especially in countries where tourism subsidizes meaningfully to GDP, is that benefits accumulating from industry do not trickle down to local societies, even in those areas where tourist activity is leading. This could be credited to lack of sufficient social capital.

Literature have shown that the more the local public participation in tourism development through the various community-based initiatives, the higher the welfares that accumulate to them [31]. Community-based initiatives, consequently, have the possible to benefit communities and offer a progressive route through which support networks could be well-known [32]. SWOT Analysis of Madagascar's Tourism Sector can be seen in Table 2. This analysis has been done by United Nations Economic Commission for Africa UNECASRO-EA, 2011.

\section{Strategies for Improving Tourism Linkages in Madagascar}

Due to the fact that tourism has been recognized as one of the key sector to drive economic growth and that the usual model has not brought about expressive socio-economic growth, a number of approaches have been planned to enhance tourism economic linkages. [34] for illustration, suggests several measures that evolving countries can pursue to improve tourism economic linkages including: a) boosting procurement from local enterprise; b) partnerships with neighbours; c) supporting local cultural and heritage product development coupled with enhancing the capacity of local entrepreneurs to deliver these products and d) encouraging tourist expenditure within the local economy. Attaining this goal will need suitable policy interferences that encourage local community involvement in tourism, such as capacity-building for local businesspersons to permit them meet industry standards, and those policies that encourage stockholders to partner efficiently with local communities. Additional, it is significant to note that important improvements to the tourist industry can be realized through regional addition, thus cumulative the abilities of obtaining inputs within the area (e.g., through Madagascar manufactures). In adding, new notions of tourism progress that supposedly improve linkages including ecotourism and community-based tourism will have to be trained to ensure a balanced method in meeting respective country significances under broad sustainability measurements of economic, environmental and socio-cultural concerns.

\section{Conclusions and Recommendations}

As we can say Madagascar is a paradise on earth due to its beauty and abundant attractive scenery. The government has a big portion of GDP which gets from this sector, but as per my conclusion, it can increase more if we try to develop the strong DMS in the country along with strong ICT system. The research proves that DMO within Madagascar does understand the importance of realizing DMS and those they can deliver the destination with modest advantage and long-term welfares. An important number of DMS are not subcontracting DMS regardless of the advantages can be gained. The DMS still prefer to purchase the system and few proceed to build their own DMS, lack of funding and scientific expertise are seen as two of the major obstacles. DMS not only

\section{Table 2. SWOT analysis of Madagascar's tourism sector.}

SWOT analysis of Madagascar's Tourism sector KEY STRENGTHS

- One of the world's top "biodiversity hotspots”

- Rich natural heritage-more than $80 \%$ of Madagascar's flora and fauna are found nowhere else in the world and some taxonomic groups, including reptiles and amphibians, are over $95 \%$ endemic

- Coastal attractions

\section{KEY OPPORTUNITIES}

- Investment finance through the "Funds For the Promotion of Private Business”

- Tourism product diversification e.g. adventure, special interest etc.

- Establishment of ecotourism investment zones

- $\quad$ Emerging markets in Africa and Asia

\section{KEY WEAKNESSES}

- Lack of supportive policies and regulations

- Investment climate is not conducive to tourism development

- Weak country credit rating

- Unfavorable labour relations in the hospitality sector

- $\quad$ Poor airline connectivity

- Inadequately skilled labour-force

- Inadequate funding for tourism initiatives

- $\quad$ Stiff competition from neighbouring tourism destinations such as Seychelles and Mauritius

\section{KEY THREATS}

- Lack of an “open skies” policy

- $\quad$ Perceptions of poor governance and political instability

- $\quad$ degree of environmental and forest degradation

- Climate change

- Disaster vulnerability e.g. drought, cyclones, flooding, etc.

Source: (UNECASRO-EA, 2011) [33]. 
help the traveler, but also increase the economy of any country, a country like Madagascar, which is a developing country, not only need to create these types of system itself, but the government should also encourage DMS system in the country for the foreigner investors. The vendors of DMO are also responsible to create a confirmatory environment for the tourists, develop the market demand and driven tourism packages, expand the service quality and product development of local suppliers and improve the environmental performance of private businesses. To support sustainable tourism development, promote responsible travel and give incentives to travelers to understand and protect the local culture and environment they are visiting. Government of Madagascar should take some serious and suitable steps for the betterment of this sector because SWOT analyses that the weakness and threats of this sector are high. Apart from it, a large number of Madagascar people attach with this profession, so by the betterment of this sector, government can promote the economy of the country as well as the life of people. A sustainable and developed DMS are in need of time for this sector within country.

\section{References}

[1] Varghese, B. (2013) Intervention of Destination Management Organization's in Tourist Destinations for Branding, Image Building and Competitiveness-A Conducive Model for Karnataka. International Journal of Investment and Management, 2, 50-56. http://dx.doi.org/10.11648/j.jim.20130203.13

[2] Jacobson, D. and Andreosso-O’Callaghan, B. (1996) Industrial Economics and Organization. McGraw-Hill, Maidenhead.

[3] Pearce, D.G. (1997) Competitive Destination Analysis in Southeast Asia. Journal of Travel Research, 35, 16-24.

[4] Buhalis, D. (2000) Marketing the Competitive Destination of the Future. Tourism Management, 21, 97-116. http://dx.doi.org/10.1016/S0261-5177(99)00095-3

[5] Gretzel, U., Yuan, Y.L. and Fesenmaier, D.R. (2000) Preparing for the New Economy: Advertising Strategies and Change in Destination Marketing Organizations. Journal of Travel Research, 39, 146-156. http://dx.doi.org/10.1177/004728750003900204

[6] Sheldon, P. (1997) Tourism Information Technology. CAB International, New York.

[7] Buhalis, D. (1997) Information Technology as a Strategic Tool for Economic, Social, Cultural and Environmental Benefits Enhancement of Tourism at Destination Regions. Progress in Tourism and Hospitality Research, 3, 71-93. http://dx.doi.org/10.1002/(SICI)1099-1603(199703)3:1<71::AID-PTH42>3.0.CO;2-T

[8] Frew, A.J. and O’Connor, P. (1998) A Comparative Examination of the Implementation of Destination Marketing System Strategies: Scotland and Ireland. In: Buhalis, D. and Schertler, W., Eds., Information and Communication Technologies in Tourism1998. Springer, Wien-New York, 258-267.

[9] Sheldon, P.J. (1993) Destination Information Systems. Annals of Tourism Research, 20, 633-649. http://dx.doi.org/10.1016/0160-7383(93)90088-K

[10] O’Connor, P. (2002) The Changing Face of Destination Management Systems. Travel and Tourism Analyst, No. 2, $1-25$.

[11] Lewis, R.D. (2002) Modelling Tourism Impacts Using IT Based DMS. In: Fesenmaier, D., Klein, S. and Buhalis, D., Eds., Information and Communication Technologies in Tourism, Springer, Wien-New York, 97-104.

[12] Gretzel, U., Yuan, Y.L. and Fesenmaier, D.R. (2000) Preparing for the New Economy: Marketing Strategies and Change in Destination Marketing Organizations. Journal of Travel Research, 39, 146-156. http://dx.doi.org/10.1177/004728750003900204

[13] Smith, S. (1995) Tourism Analysis: A Handbook. 2nd Edition, Longman, London.

[14] Cooper, C., Fletcher, J., Gilbert, D. and Wanhill, S. (1998) Tourism: Principles and Practice. Pitman, London.

[15] Sharpley, R. and Telfer, D.J. (2002) Tourism and Development: Concepts and Issues. Channel View Publications, Clevedon.

[16] Milne, S. and Ateljevic, I. (2001) Tourism, Economic Development and the Global-Local Nexus: Theory of Embracing Complexity. Tourism Geographies, 3, 369-393. http://dx.doi.org/10.1080/146166800110070478

[17] UNWTO (2010) Manual on Tourism and Poverty Alleviation—Practical Steps for Destinations. Madrid. http://pub.unwto.org/WebRoot/Store/Shops/Infoshop/4BEB/F726/BC4B/3784/9088/C0A8/0164/FDA7/100513 manua l_pov_all_excerpt.pdf

[18] WTO-World Tourism Organisation (2007) A Practical Guide to Tourism Destinationv Management. WTO Business Council, Madrid.

[19] Sigala, M. and Marinidis, D. (2009) Exploring the Transformation of Tourism Firms' Operations and Business Models through the Use of Web Map Services. European and Mediterranean Conference on Information Systems 2009, Izmir, 
13-14 July 2009, 1-13.

[20] Wang, Y. and Fesenmaier, D. (2006) Identifying the Success Factors of Web-Based Marketing Strategy: An Investigation of Convention and Visitors Bureaus in the United States. Journal of Travel Research, 44, 239-249. http://dx.doi.org/10.1177/0047287505279007

[21] Chen, H.M. and Sheldon, P. (1997) Destination Information Systems: Design Issues and Directions. Journal of Management Information Systems, 14, 151-176.

[22] Frew, A.J. and Horan, P. (2007) Destination Website Effectiveness: A Delphi Study-Based eMetric Approach. HITA Conference, Orlando, 49-80.

[23] Frew, A.J. and O’Connor, P. (1999) DMS: Refining \& Extending an Assessment Framework. In: Buhalis, D. and Schertler, W., Eds., ICT in Tourism, Springer, Wien, 398-407.

[24] UNCTAD (2007) FDI in Tourism: The Development Dimension. United Nations.

[25] De Villiers, D. (2005) Small Islands Big Stakes. Opening Speech, The United Nations Conference on Small Islands, Port-Louis, 10-14 January 2005.

[26] World Economic Forum (2009) The Travel and Tourism Competitiveness Index 2009: Measuring Sectoral Drivers in a Downturn. World Economic Forum, Cologny.

[27] WTTC (2010) Travel and Tourism Economic Impacts: Country Reports 2010. London.

[28] Lazear, E.P. (2004) Balanced Skills and Entrepreneurship. American Economic Review, 94, 208-211. http://dx.doi.org/10.1257/0002828041301425

[29] Victurine, R. (2000) Building Tourism Excellence at the Community Level: Capacity Building for Community-Based Entrepreneurs in Uganda. Journal of Travel Research, 38, 221-229. http://dx.doi.org/10.1177/004728750003800303

[30] Doswell, R. (2000) African Tourism Training and Education: Hits and Misses. In: Dieke, P.U.C., Ed., The Political Economy of Tourism Development in Africa, Cognizant Communication Corporation, USA, 247-259.

[31] Mitchell, R.E. and Reid, D.G. (2001) Community Integration: Island Tourism in Peru. Annals of Tourism Research, 28, 113-139. http://dx.doi.org/10.1016/S0160-7383(00)00013-X

[32] Manyara, G. and Jones, E. (2007) Community-Based Tourism Enterprises Development in Kenya: An Exploration of Their Potential as Avenues of Poverty Alleviation. Journal of Sustainable Tourism, 15, 628-644. http://dx.doi.org/10.2167/jost723.0

[33] UNECASRO-EA (2011) Towards a Sustainable Tourism Industry in Eastern Africa: A Study on the Challenges and Opportunities for Tourism Development. United Nations Economic Commission for Africa, Addis Ababa.

[34] ODI (2006) Tourism Business and the Local Economy: Increasing Impact through a Linkages Approach. ODI Briefing Paper, March 2006. http://www.odi.org.uk/resources/download/1944.pdf 
Scientific Research Publishing (SCIRP) is one of the largest Open Access journal publishers. It is currently publishing more than 200 open access, online, peer-reviewed journals covering a wide range of academic disciplines. SCIRP serves the worldwide academic communities and contributes to the progress and application of science with its publication.

Other selected journals from SCIRP are listed as below. Submit your manuscript to us via either submit@scirp.org or Online Submission Portal.
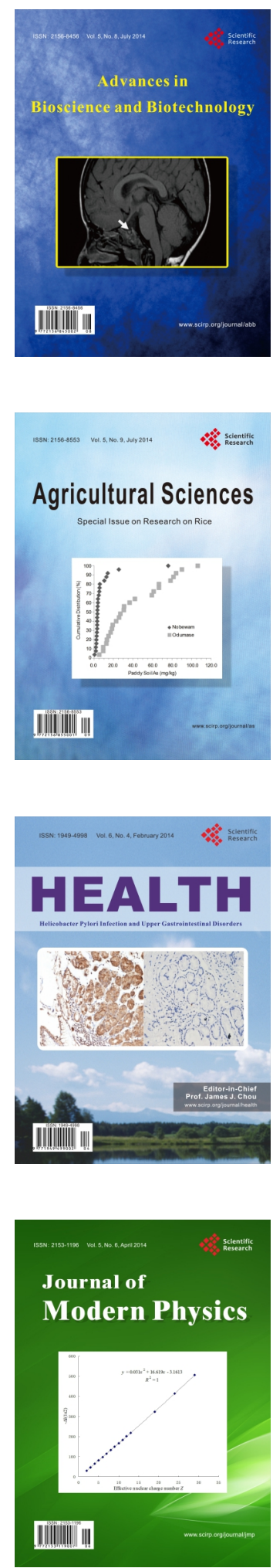
